\title{
Terapia neural e auto hemoterapia, pH e condutividade de misturas de sangue com cloridrato de procaína
}

\author{
Leonardo Rocha Vianna ${ }^{a}$, Bruna Aparecida Lima Gonçalves ${ }^{b}$
}

\author{
${ }^{a}$ Acupunturista, Medicina Tradicional Chinesa, Homeopata, Terapeuta Neural, Iridologista, Fitoterapeuta, Quiroprata. \\ Universidade Federal de Minas Gerais (UFMG), Belo Horizonte, MG, Brasil. \\ ${ }^{b}$ Acupunturista, Medicina Tradicional Chinesa, Terapeuta Neural. Universidade Federal de Minas Gerais (UFMG), Belo \\ Horizonte, MG, Brasil.
}

RESUMO A terapia neural é um tratamento que objetiva a auto regulação do organismo através da aplicação de anestésicos locais em baixas concentrações, como o cloridrato de procaína, em locais escolhidos pela história de vida do paciente. A terapia neural é difundida na Alemanha, Áustria, Argentina, Canadá, Colômbia, Costa Rica, Cuba, Espanha, Estados Unidos, México, Suíça. Os anestésicos locais em baixas concentrações funcionam como drogas dielétricas e atuam no potencial de membrana das células enfermas. A associação com a auto hemoterapia e hemopuntura é benéfica. $\mathrm{O}$ objetivo desse trabalho é demonstrar a condutividade e o $\mathrm{pH}$ do sangue total juntamente com o cloridrato de procaína a 0,7\% com bicarbonato de sódio em várias proporções. Cada vez mais a medicina busca novas maneiras de fazer com que o corpo responda às agressões dos microrganismos de uma forma prática, simples e de baixo custo. A associação da Terapia Neural com a auto-hemoterapia e hemopuntura na prática clínica potencializa futuros tratamentos.

PALAVRAS-CHAVE: anestésicos locais; auto regulação; hemopuntura; imunidade; repolarização.

Aceito 4 de dezembro de $2020 \quad$ Publicado online 26 de janeiro de 2021

Cite este artigo: Vianna e Gonçalves (2021) Terapia neural e auto hemoterapia, pH e condutividade de misturas de sangue com cloridrato de procaína.

Multidisciplinary Science Journal 3: e2021004, doi: 10.29327/multiscience.2021004.

\section{Neural therapy and auto hemotherapy, $\mathrm{pH}$ and conductivity of blood mixtures with procaine hydrochloride}

ABSTRACT Neural Therapy is a treatment that aims at self-regulation of the organism through the application of local anesthetics in low concentrations, such as procaine hydrochloride, in places chosen by the patient's life history. Neural Therapy is widespread in Germany, Austria, Argentina, Canada, Colombia, Costa Rica, Cuba, Spain, United States, Mexico, Switzerland. Local anesthetics in low concentrations work as dielectric drugs and act on the membrane potential of diseased cells. The association with auto hemotherapy and hemopuncture is beneficial. The objective of this work is to demonstrate the conductivity and $\mathrm{pH}$ of whole blood together with $0.7 \%$ procaine hydrochloride with sodium bicarbonate in various proportions. More and more medicine is looking for new ways to make the body respond to the aggressions of microorganisms in a pratical, simples and low cost way. The association of Neural Therapy with auto hemotherapy and hemopuncture in clinical practice enhances treatments.

KEYWORDS: local anesthetics; self-regulation; hemopuncture; immunity; repolarization.

\section{Introdução}

A terapia neural nasce principalmente dos trabalhos de Pavlov e Speransky durante o movimento científico e cultural conhecido como nervismo na Rússia, que embasou as investigações científicas na Alemanha e de outros países europeus. Esta teoria considera o papel do sistema nervoso em todos os processos curativos e patológicos do organismo (Jiménez 2010, Toscano e Bonilla 2012). 
A terapia neural é um tratamento que visa a autorregulação do paciente, mediante aplicações de substâncias dielétricas como os anestésicos locais em baixas concentrações. Através da história de vida do paciente, busca-se a descoberta de campos interferentes e os neutraliza mediante a aplicação de substâncias neurais terapêuticas (López et al 2012). Os anestésicos locais promovem a repolarização celular nos campos interferentes (locais afetados que geram alterações e enfermidades a distância), regiões em que as células estão despolarizadas. Quando se aplica substâncias dielétricas em células enfermas, essas se repolarizam e o potencial da membrana celular é restabelecido, podendo levar à cura (Calderón et al 2002; Vianna e Gonçalves 2016).

Cada célula normal apresenta o potencial de membrana de \pm 40 a $\pm 90 \mathrm{mV}$. Quando se aplica um estímulo, essa se depolariza e normalmente se repolariza de imediato (Calderón et al 2002). Mas quando a célula sofre estímulos constantes, perde essa capacidade de repolarização e torna-se enferma (Vianna e Gonçalves 2017).

O sistema nervoso atua em um sistema de rede, coordenando e integrando as informações internas e teciduais do indivíduo e sua resposta adaptativa. Por isso, se um estímulo irritante entrar em contato com o organismo, ele poderá comprometê-lo como um todo, gerando processos patológicos locais ou distantes do sítio inicial de irritação (Speransky 1954).

A terapia neural é um sistema terapêutico que exerce sua ação sobre o sistema neurovegetativo mediante aplicações de anestésicos locais em baixas concentrações, como a procaína e lidocaína. Em 1928 os irmãos alemães Huneke publicaram "Efeitos desconhecidos a distância dos anestésicos locais" onde descreveram suas experiências, com o medicamento Impletol (procaína mais cafeína) (Calderón et al 2002). É um tratamento seguro (Bella 2011).

Os anestésicos locais possuem 290 mV (Castro 2011), mas segundo Vianna e Gonçalves (2020), o cloridrato de procaína a 0,7\% apresenta até $207 \mathrm{mV}$. Em um estudo em cães com dermatite atópica, utilizou a dose máxima de 7 $\mathrm{mg} / \mathrm{kg}$ de cloridrato de procaína 0,7\% de forma intradermal (Bravo-Monsalvo et al 2008). A procaína é um éster metabolizado pelas acetilcolinesterases (Bella 2011).

A associação do cloridrato de procaína com bicarbonato de sódio forma um "cluster" que altera o pH e diminui o ardor no momento da aplicação. A administração endovenosa demonstrou ação antirreumática, antitumoral, antiinflamatória, analgésica e aumento da vitalidade nos pacientes (Reuter 2017). Sabe-se também da ação antimicrobiana dos anestésicos locais (Cassuto et al 2006, Gonçalves et al 2020).

A acupuntura e a terapia neural são medicinas complementares regulatórias e minimamente invasivas, praticamente desprovidas de efeitos colaterais que estão relacionadas entre si e seguem uma linha de visão integral do paciente (Weinschenk 2012). Algumas cicatrizes podem estar presentes em meridianos de acupuntura e, por conta disso, podendo levar à um bloqueio energético destes. Assim, essas cicatrizes podem se comportar como campos interferentes (Bella 2011). Os anestésicos locais ajudam a liberar a estagnação energética dos canais da acupuntura (Bayona 2018).

Segundo Castro (2011), pode-se realizar a terapia neural das seguintes formas: pomadas, nebulização, gotas oculares, nasal, perilesional, peri venosa, peri orgânica, no canal medular, cicatrizes, nas veias e arterias, zonas head, metâmeros, pontos gatilhos e associada a auto-hemoterapia. É possível também aplicar em dermátomos ou gânglios (Bella 2011).

Sabe-se da correlação de $71 \%$ entre os pontos gatilhos e os pontos de acupuntura tradicionais para o tratamento da dor (Quattrer 2016). Estudos recentes evidenciaram a relação entre dermátomos e os canais da Medicina Tradicional Chinesa e pontos de acupuntura, demonstrando os pontos de dor máxima descritos por Head em cada uma de suas zonas, comparando-os anatomicamente com pontos de acupuntura, pontos de alarme $(\mathrm{Mu})$ e assentimento nervosos ou dorsais (Shu), encontrando uma clara correlação das zonas de Head nas áreas de pulmão, estômago, fígado e rim/ureter. A medicina tradicional chinesa descreve há muitos anos os canais de energia, onde 235 acupontos correlacionam-se com zonas head. De acordo com Head, em 1898, algumas enfermidades viscerais são refletidas em regiões sensíveis na pele (Molano et al 2014).

A terapia neural é difundida na Alemanha, Áustria, Argentina, Canada, Colômbia, Costa Rica, Cuba, Espanha, Estados Unidos, México, Suíça (Vianna e Gonçalves 2016). Segundo De La Torres Roses e Mendoza (2008), pode ser utilizada em problemas reumáticos, neurológicos, ginecológicos, enxaquecas, amigdalites, sinusites, otites, asma, afecções dermatológicas dentre outras. Também é utilizada para a dor miofacial, dor visceral, síndrome de dor pós 
amputação, neuralgia herpética, vaginismo, colite crônica, zumbido auditivo (tinidos), quadros oncológicos e Alzheimer (Weinschenk 2012).

Segundo Fontaines e Pérez (2020), tanto a acupuntura, quanto a terapia neural e a auto hemoterapia podem tratar a Psoríase. A "auto-hemoterapia menor" é uma técnica simples e de baixo custo, que consiste em retirar de 2 a $10 \mathrm{ml}$ de sangue e aplicar principalmente por via intramuscular (dependendo do objetivo por via subcutânea), o qual estimula o sistema imunológico e aumenta o nível de macrófagos de $5 \%$ a $22 \%$ no sangue periférico. Pode ser utilizada em diversas enfermidades como: acne, alergias, anemia, amigdalites agudas ou recorrentes, artroses, artrites, asma, quadros oncológicos, diabetes, processos autoimunes, esclerodermia, esclerose múltipla, gota, hepatites, hipertensão, mioma, púrpura, ovário policístico, asma, bronquite, artrite reumatoide e como preventivo para infecções causadas por microrganismos oportunistas devido a sua ação imuno-estimulante (Fontaines e Pérez 2020).

A utilização da auto hemoterapia em pontos de acupuntura (hemopuntura) no pós-operatório de equinos submetidos a orquiectomia (castração convencional), demonstrou efeitos analgésico e anti-inflamatório. Ocorre no local da aplicação o aumento da circulação sanguínea pela resposta inflamatória induzida pelo sangue (Santos et al 2020).

O objetivo deste trabalho foi analisar o $\mathrm{pH}$ e a condutividade de misturas de sangue humano total e cloridrato de procaína a $0,7 \%$ com bicarbonato de sódio em diferentes proporções. Cada vez mais a medicina busca novas maneiras de fazer com que o corpo responda às agressões dos microrganismos de uma forma prática, simples e de baixo custo. A associação da Terapia Neural com a auto-hemoterapia e hemopuntura na prática clínica potencializa os tratamentos.

\section{Material e Métodos}

As soluções foram preparadas utilizando cloridrato de procaína $50 \%$ e bicarbonato de sódio $8,4 \%$ em solução fisiológica a $0,9 \%$. Como exemplo: Para obter uma diluição de cloridrato de procaína a $0,7 \%$, mistura se em uma bolsa de $250 \mathrm{ml}$ de solução fisiológica 0,9\%, 3,5 $\mathrm{ml}$ de cloridrato de procaína a $50 \%$ e 5,0 $\mathrm{ml}$ de bicarbonato de sódio a 8,4\%. Retira-se anteriormente da bolsa de solução fisiológica o volume injetado, que nesse caso foi $8,5 \mathrm{ml}$, e o volume extra da bolsa que normalmente é de $5 \%$ do seu volume total.

Os materiais utilizados na coleta sanguínea foram: seringas plásticas descartáveis de $5 \mathrm{ml}$, agulhas descartáveis $25 \times 7$, tubos de vidro de coleta de sangue, luvas descartáveis, garrote, algodão e álcool $70 \%$. Após o uso estes materiais, estes foram eliminados em locais específicos para o descarte, obedecendo às normas contidas no manual de Biossegurança.

Foram realizadas medições de sangue total masculino e feminino com soro fisiológico $0,9 \%$, sangue total masculino e feminino com anticoagulantes EDTA e citrato de sódio, misturas de sangue total com anticoagulante associados com cloridrato de procaína a 0,7\% contendo bicarbonato de sódio, e mistura de sangue total masculino com a solução de cloridrato de procaína a 0,7\% com bicarbonato de sódio. As bolsas fisiológicas utilizadas foram diluídas há 24 horas (sangue feminino) e há 21 dias (sangue masculino).

Em seringa de $5 \mathrm{ml}$ que já continha $1 \mathrm{ml}$ de solução fisiológica a 0,9\% foi realizada a coleta de $4 \mathrm{ml}$ de sangue e realizada a homogeneização e medição imediata. Para análise do sangue com anticoagulante: coletou o sangue em uma seringa já com o anticoagulante e realizou a homogeneização. Foram utilizados dois tipos de anticoagulantes, o citrato de sódio e o EDTA (ácido etilenodiamino tetra-acético). Com uma seringa de $5 \mathrm{ml}$ que continha $1,8 \mathrm{ml}$ de citrato de sódio foi coletado $3,2 \mathrm{ml}$ de sangue. Com outra seringa de $5 \mathrm{ml}$ que continha $1,0 \mathrm{ml}$ de EDTA foi coletado $4 \mathrm{ml}$ de sangue. A solução de cloridrato de procaína a $0,7 \%$ e bicarbonato de sódio foi sendo acrescentada aos tubos com sangue e anticoagulante ao longo das medições e de acordo com as proporções desejadas. Com seringa de $5 \mathrm{ml}$ que cotinha $1 \mathrm{ml}$ de solução de cloridrato de procaína a $0,7 \%$ com bicarbonato de sódio, coletou-se $4 \mathrm{ml}$ de sangue total masculino. As medições foram realizadas logo após as coletas.

Os dados foram obtidos através da análise das substâncias em triplicatas e aplicou-se análise estatística descritiva da média com desvio padrão.

Neste trabalho foi utilizado o aparelho phmetro e condutivímetro de bancada da marca Quimics, o qual possui dois eletrodos, um de metal e outro de vidro (Figura 1). 


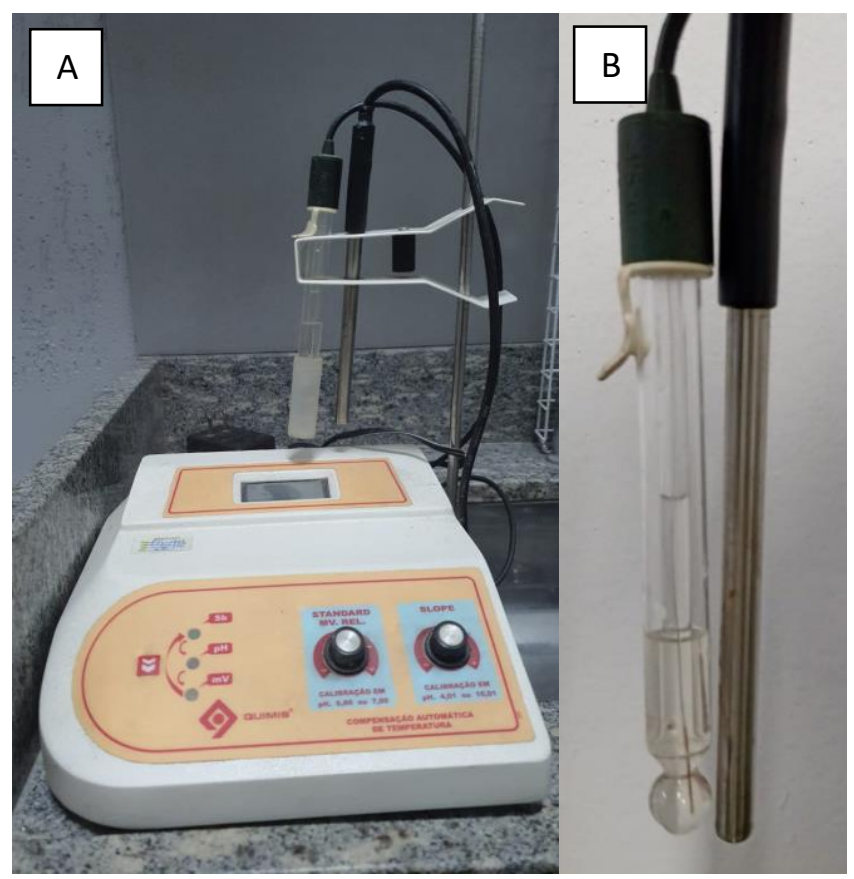

Figura 1 (A) Aparelho utilizado para as medições de pH e condutividade das substâncias. (B) eletrodos para as medições.

\section{Resultados e Discussão}

Foram realizadas as avaliações de $\mathrm{pH}$ e condutividade do sangue total com soro fisiológico e sangue total masculino com solução de cloridrato de procaína a $0,7 \%$ com bicarbonato de sódio; de sangue total masculino com EDTA e com solução de cloridrato de procaína a $0,7 \%$ com bicarbonato de sódio; de sangue total masculino com citrato de sódio e com solução de cloridrato de procaína a $0,7 \%$ com bicarbonato de sódio; de sangue total feminino com EDTA e com solução de cloridrato de procaína a $0,7 \%$ com bicarbonato de sódio e de sangue total feminino com citrato de sódio e com solução de cloridrato de procaína a $0,7 \%$ com bicarbonato de sódio, conforme mostradas abaixo, nas tabelas 1 a 5 .

Tabela 1 Avaliação de pH e condutividade do sangue total com soro fisiológico e sangue total masculino com solução de cloridrato de procaína a $0,7 \%$ com bicarbonato de sódio.

\begin{tabular}{lcc}
\hline \multicolumn{1}{c}{ Produto testado } & pH & Condutividade (mV) \\
\hline $\begin{array}{l}\text { Sangue total com solução fisiológica } \\
\text { 0,9\% -Masculino }\end{array}$ & $7,05 \pm 0,16$ & $-75,00 \pm 0,18$ \\
$\begin{array}{l}\text { Sangue total com solução de cloridrato } \\
\text { de procaína a 0,7\% com bicarbonato de } \\
\text { sódio diluída há 21 dias - Masculino }\end{array}$ & $7,15 \pm 0,11$ & $-107,00 \pm 0,16$ \\
$\begin{array}{l}\text { Sangue total com solução fisiológica } \\
\text { 0,9\% -Feminino }\end{array}$ & $5,22 \pm 0,37$ & $-112,25 \pm 0,50$ \\
\hline
\end{tabular}

Tabela 2 Avaliação de pH e condutividade de sangue total + EDTA + solução de cloridrato de procaína a 0,7\% com bicarbonato de sódio - sangue masculino.

\begin{tabular}{lcc}
\hline \multicolumn{1}{c}{ Produto testado } & pH & Condutividade $(\mathbf{m V})$ \\
\hline $\begin{array}{l}\text { Sangue com EDTA - masculino } \\
\text { Sangue com EDTA 90 \% com 10\% da solução de cloridrato } \\
\text { de procaína a 0,7\% diluída há 21 dias - masculino }\end{array}$ & $6,09 \pm 0,18$ & $-52,00 \pm 0,25$ \\
$\begin{array}{l}\text { Sangue com EDTA 75\% com 25\% da solução de cloridrato } \\
\text { de procaína a 0,7\% diluída há 21 dias - masculino }\end{array}$ & $6,97 \pm 0,25$ & $-94,50 \pm 0,44$ \\
$\begin{array}{l}\text { Sangue com EDTA 50\% com 50\% da solução de cloridrato } \\
\text { de procaína a 0,7\% diluída há 21 dias - masculino }\end{array}$ & $7,04 \pm 0,19$ & $-74,00 \pm 0,28$ \\
$\begin{array}{l}\text { Sangue com EDTA 25\% com 75\% da solução de cloridrato } \\
\text { de procaína a 0,7\% diluída há 21 dias - masculino }\end{array}$ & $7,10 \pm 0,14$ & $-79,50 \pm 0,24$ \\
\hline
\end{tabular}


Tabela 3 Avaliação de pH e condutividade de sangue total + citrato de sódio + solução de cloridrato de procaína a 0,7\% com bicarbonato de sódio - sangue masculino.

\begin{tabular}{lcc}
\hline \multicolumn{1}{c}{ Produto testado } & pH & Condutividade (mV) \\
\hline $\begin{array}{l}\text { Sangue com citrato - masculino } \\
\begin{array}{l}\text { Sangue com citrato de sódio 90\% com 10\% da solução de } \\
\text { cloridrato de procaína a 0,7\% diluída há 21 dias - masculino }\end{array}\end{array}$ & $7,10 \pm 0,06$ & $-85,00 \pm 0,38$ \\
$\begin{array}{l}\text { Sangue com citrato de sódio 75\% com 25\% da solução de } \\
\text { cloridrato de procaína a 0,7\% diluída há 21 dias - masculino }\end{array}$ & $7,15 \pm 0,15$ & $-82,50 \pm 0,41$ \\
$\begin{array}{l}\text { Sangue com citrato de sódio 50\% com 50\% da solução de } \\
\text { cloridrato de procaína a 0,7\% diluída há 21 dias - masculino }\end{array}$ & $6,90 \pm 0,17$ & $-96,50 \pm 0,32$ \\
$\begin{array}{l}\text { Sangue com citrato de sódio 25\% com 75\% da solução de } \\
\text { cloridrato de procaína a 0,7\% diluída há 21 dias - masculino }\end{array}$ & $6,79 \pm 0,12$ & $-68,75 \pm 0,27$ \\
\hline
\end{tabular}

Tabela 4 Avaliação de pH e condutividade de sangue total + EDTA + solução de cloridrato de procaína a 0,7\% com bicarbonato de sódio - sangue feminino.

\begin{tabular}{lcc}
\hline \multicolumn{1}{c}{ Produto testado } & pH & Condutividade (mV) \\
\hline $\begin{array}{l}\text { Sangue com EDTA - Feminino } \\
\text { Sangue com EDTA 90 \% com 10\% da solução de cloridrato } \\
\text { de procaína a 0,7\% diluída há 24 horas - feminino }\end{array}$ & $5,67 \pm 0,06$ & $-130,75 \pm 0,08$ \\
$\begin{array}{l}\text { Sangue com EDTA 75\% com 25\% da solução de cloridrato } \\
\text { de procaína a 0,7\% diluída há 24 horas - feminino }\end{array}$ & $6,20 \pm 0,43$ & $-149,25 \pm 0,44$ \\
$\begin{array}{l}\text { Sangue com EDTA 50\% com 50\% da solução de cloridrato } \\
\text { de procaína a 0,7\% diluída há 24 horas - feminino }\end{array}$ & $5,70 \pm 0,42$ & $-159,50 \pm 0,59$ \\
$\begin{array}{l}\text { Sangue com EDTA 25\% com 75\% da solução de cloridrato } \\
\text { de procaína a 0,7\% diluída há 24 horas - feminino }\end{array}$ & $6,13 \pm 0,40$ & $-129,00 \pm 0,52$ \\
\hline
\end{tabular}

Tabela 5 Avaliação de pH e condutividade de sangue total + citrato de sódio + solução de cloridrato de procaína a 0,7\% com bicarbonato de sódio - sangue feminino.

\begin{tabular}{lcc}
\hline \multicolumn{1}{c}{ Produto testado } & pH & Condutividade (mV) \\
\hline $\begin{array}{l}\text { Sangue com citrato - feminino } \\
\text { Sangue com citrato de sódio 90\% com 10\% da solução de }\end{array}$ & $5,98 \pm 0,22$ & $-158,50 \pm 0,34$ \\
$\begin{array}{l}\text { cloridrato de procaína a 0,7\% diluída há 24 horas - feminino } \\
\text { Sangue com citrato de sódio 75\% com 25\% da solução de } \\
\text { cloridrato de procaína a 0,7\% diluída há 24 horas - feminino }\end{array}$ & $6,14 \pm 0,05$ & $-162,00 \pm 0,43$ \\
$\begin{array}{l}\text { Sangue com citrato de sódio 50\% com 50\% da solução de } \\
\text { cloridrato de procaína a 0,7\% diluída há 24 horas - feminino }\end{array}$ & $6,19 \pm 0,31$ & $-159,25 \pm 0,32$ \\
$\begin{array}{l}\text { Sangue com citrato de sódio 25\% com 75\% da solução de } \\
\text { cloridrato de procaína a 0,7\% diluída há 24 horas - feminino }\end{array}$ & $6,30 \pm 0,17$ & $-177,25 \pm 0,22$ \\
\hline
\end{tabular}

Segundo Vianna e Gonçalves (2020), a condutividade da solução diminui com o tempo, sendo que uma solução mais nova possui maior condutividade do que uma diluída ou fabricada há mais tempo. Já o pH da solução nova é mais ácido que o pH da solução com 21 dias após a diluição. Conforme demonstrado na tabela 6:

Tabela 6 Avaliação de condutividade e pH de solução de cloridrato de procaína a 0,7\% com bicarbonato de sódio diluída há 24 horas e há 21 dias.

\begin{tabular}{lcc}
\hline \multicolumn{1}{c}{ Produto testado } & pH & Condutividade (mV) \\
\hline $\begin{array}{l}\text { Cloridrato de Procaína 0,7\% c/ Bicarbonato de } \\
\text { sódio diluída há 21 dias }\end{array}$ & $7,24 \pm 0,06$ & $-93,0 \pm 0,06$ \\
$\begin{array}{l}\text { Cloridrato de Procaína 0,7\% c/ Bicarbonato de } \\
\text { sódio diluída há 24 h }\end{array}$ & $6,65 \pm 0,47$ & $-207,00 \pm 0,04$ \\
\hline
\end{tabular}

Fonte: Vianna e Gonçalves (2020).

O EDTA é recomendado como o anticoagulante de escolha para coleta das amostras na realização do hemograma. Este não induz modificações da membrana celular e consequentemente não produz alterações morfológicas nas células sanguíneas (Seniv et al 2017).

As amostras de sangue coletado com o anticoagulante EDTA podem ser refrigeradas a $4{ }^{\circ} \mathrm{C}$ por até $24 \mathrm{~h}$ com mínimas alterações nos valores da série vermelha (Franco 2007). As amostras sanguíneas, conservadas por 48 horas, mantém boas condições para análise, principalmente quando armazenadas à temperatura de 2 a $8{ }^{\circ} \mathrm{C}$. A concentração 
de EDTA e o tempo de armazenagem não influencia os resultados da contagem de leucócitos. O número de plaquetas também não apresenta alteração (Oliveira et al 2010).

O citrato de sódio é um anticoagulante que impede a coagulação sanguínea, bem como promove a estabilização da membrana eritrocitária auxiliando na manutenção do pH intracelular (Sousa et al 2012). A estocagem em soluções anticoagulantes objetiva manter a viabilidade e a função de cada constituinte sanguíneo. Também busca prevenir alterações físicas prejudiciais nos seus componentes e evitar a proliferação bacteriana (Junior et al 2008). Quando o sangue coletado é armazenado em soluções conservadoras, uma das principais alterações que ocorre é a redução do $\mathrm{pH}$, visto que as células continuam seu metabolismo. O tempo de armazenamento sanguíneo humano refrigerado varia de 21 a 49 dias, dependendo da solução conservante utilizada (Sousa et al 2012).

Segundo Suzuki (2009), Neumann e Rosenhech demostraram na década de 70, que a aplicação de campos elétricos aumenta a permeabilidade da membrana plasmática em vesículas. A dinâmica de abertura e fechamento, bem como o tamanho e quantidade de poros sofrem a influência de fatores como campo elétrico aplicado e propriedades do meio celular. Aplicação de um campo elétrico externo provoca um aumento da mobilidade dos fosfolipídios. Quando um tecido biológico ou uma suspensão de células são excitados por um campo elétrico externo, ocorrem movimentações iônicas no eletrólito e íons acumulam-se em ambos os lados da membrana celular. O DNA é flexível e sujeito à orientação e deformação na presença de um campo elétrico. Verificou-se que o aumento da condutividade externa, principalmente para as condições in vivo, possibilita maior condutância da membrana (Suzuki 2009, Ramos 2014).

Segundo Fraceto e Paula (2004), os anestésicos locais têm afinidade pela membrana celular e, de acordo com Bayona (2018), na terapia neural não se busca o efeito anestésico, mas sim a ação dielétrica da procaína, a qual eleva a polaridade da célula enferma que se encontra despolarizada. Pela ação dielétrica a procaína tem a capacidade de interagir com o corpo humano, que é um campo eletromagnético em si. Após a administração, ela entra em contato com a célula alterada e, com seu potencial de ação, tem a capacidade de atuar sobre sua membrana, alterar sua polarização e assim melhorar sua oxigenação. Assim, a célula inicia um processo de restauração global, desde a membrana, recuperando os processos químicos intracelulares, até o DNA, e restabele as funções celulares. Na prática clínica, é evidenciado com a diminuição dos sintomas do paciente e a melhora do estado de saúde.

A auto hemoterapia com a terapia neural consiste na mistura de sangue do próprio paciente com solução de cloridrato de procaínae posterior aplicação, seja intradérmica, subcutânea, intramuscular, em pontos de acupuntura (hemopuntura) ou aplicação no local da patologia, com o objetivo de melhora da circulação, ativação celular e melhora da imunidade (Castro 2011; Fontaines e Pérez 2020).

Como demonstram os resultados das tabelas 1 a 5, as soluções para a aplicação final de auto hemoterapia neural variam em $\mathrm{pH}$ e condutividade se o sangue estiver misturado com solução fisiológica ou com anticoagulante. Como demonstrado nas tabelas 1, 2 e 3, o sangue total masculino misturado com solução fisiológica apresenta $-75,00 \mathrm{mV}$ de condutividade. Quando misturado com solução de cloridrato de procaína a 0,7\% com bicarbonato de sódio diluída há 21 dias, apresenta $-107,00 \mathrm{mV}$. Quando misturado com o anticoagulante EDTA, apresenta $-52,00 \mathrm{mV}$ e com citrato de sódio tem $-85,00 \mathrm{mV}$. Como também mostrado nas tabelas 1, 4 e 5, o sangue total feminino com solução fisiológica apresenta -112,25 mV. Com EDTA apresenta -130,75 mV e com citrato de sódio apresenta - 158,50 mV.

Também variam de $\mathrm{pH}$ e condutividade nas diferentes proporções da mistura de sangue total com cloridrato de procaína a $0,7 \%$ e bicarbonato de sódio, como demostrado na tabela 2 . O sangue total masculino com EDTA de proporção $90 \%$ com $10 \%$ da solução de cloridrato de procaína a 0,7\% diluída há 21 dias, apresenta $-94,50 \mathrm{mV}$ de condutividade e 7,29 de $\mathrm{pH}$; já na proporção de $25 \%$ de sangue com $75 \%$ da solução de cloridrato de procaína a $0,7 \%$ apresenta -79,50 $\mathrm{mV}$ de condutividade e 7,10 de pH. Como também demostrado na tabela 4, o sangue total feminino com EDTA na proporção $90 \%$ com $10 \%$ da solução de cloridrato de procaína a 0,7\% diluída há 24 horas, apresenta $149,25 \mathrm{mV}$ de condutividade e 5,97 de pH; já na proporção de $25 \%$ de sangue com $75 \%$ da solução de cloridrato de procaína a 0,7\%, apresenta $-138,25 \mathrm{mV}$ de condutividade e 6,13 de $\mathrm{pH}$.

Os estudos das substâncias para utilização em Terapia Neural iniciam com a composição, pH e condutividade. O potencial hidrogênico $(\mathrm{pH})$ é a capacidade de um material liberar íons hidroxila indica acidez, neutralidade ou alcalinidade de uma solução, sendo o valor 7 considerado neutro, 1 muito ácido e 14 extremamente alcalino (Canali 2015). Este $\mathrm{pH}$ mais ácido e mais distante de pH 7,2 e 7,6 pode causar mais ardência no local da aplicação. Segundo 
Fernandes (2013), a condutividade elétrica de uma solução é a expressão numérica quantitativa da sua capacidade de transportar corrente elétrica. No entanto, ainda serão necessários mais estudos para compreender o valor mínimo necessário que a substância neural é capaz de causar a ativação celular de uma célula enferma.

As principais vantagens para a utilização de anticoagulante seriam o maior tempo na aplicação da mistura entre a coleta e última aplicação, o que evitaria a coagulação sanguínea e entupimento da agulha, e a estabilidade da mistura em termos de $\mathrm{pH}$ e condutividade, se comparar com a mistura sem anticoagulante devido a permanência do metabolismo celular das células sanguíneas.

\section{Conclusão}

É necessário fornecer novas evidências que nos permitam observar as alterações geradas pela procaína devido às suas características dielétricas, e não somente devido a sua ação na membrana celular. Todas as experiências nos ajudarão a entender o efeito de substâncias dielétricas sobre os sistemas celulares. Testes clínicos in vivo serão necessários para avaliar a resposta biológica da melhor mistura de sangue e cloridrato de procaína para efeitos clínicos no paciente. Na prática clínica, esta técnica possui baixo custo e ótima eficácia.

Estudos sobre a membrana celular, sua condutividade elétrica, o funcionamento dos poros celulares e as trocas entre o interior e exterior das células terão, em breve, profundo impacto na clínica prática, no tratamento e na cura de inúmeras patologias, incluindo o câncer.

A condutividade de uma substância pode fazer com que o corpo funcione melhor e de maneira mais organizada. Acreditamos que a auto hemoterapia neural e auto hemopuntura neural poderão beneficiar muitos pacientes.

\section{Agradecimentos}

Farmácia Casa das Fórmulas, Belo Horizonte/MG.

\section{Declaração de conflito de interesses}

Não há conflito de interesses entre os autores.

\section{Referências}

Bayona YPV (2018) Efecto de la acupuntura y de la terapia neural, sobre un organismo biologico como el hombre. Una posibilidad terapeutica como medicina integrativa. Dissertação de mestrado, Universidade Nacional da Colombia, Bogotá.

Bella FA (2011) Cicatrices: Teoría de los campos interferentes. Revista Española de Podologia XXII: 268-272.

Bravo-Monsalvo A, Vázquez-Chagoyán J, Gutiérrez L, Sumano H (2018) Clinical efficacy of neural therapy for the treatment of atopic dermatitis in dogs. Acta Veterinaria Hungarica 56:459-469.

Calderón JB, De La Torre Roses M, Carballo NC, Rodríguez MAB (2002) Odontología Neurofocal como parte de la Terapia Neural. Archivo Médico de Camagüey 6:1-6.

Canali LCF (2015) A interferência do sangue e soro fisiológico na solubilidade, pH e componente iônico das obturações retrógradas de MTA branco Ângelus ${ }^{\circledR}$. Dissertação de mestrado, Universidade Estadual de Maringá, Maringá

Castro RA (2011) Bases para la terapia neural em caninos y felinos. Buenos Aires: Dunken.

Cassuto J, Sinclair R, Bonderovic M (2006) Anti-inflammatory properties of local anesthetics and their present and potential clinical implications. Acta Anaesthesiologica Scandinavica 50:265-282.

De La Torres Roses MM, Mendoza RL (2008) La terapia neural: uma alternativa em el tratamiento de La litiasis renal. Revista Arch Méd Camagüey 12:1-9.

Fernandes A (2013) A medida de pH e condutividade. Apresentação SANEPAR. 29p.

Fontaines JAG, Pérez LG (2020) Acupuntura y auto-hemoterapia en puntos de acupuntura em pacientes con Psoriasis. Presentación de casos. Multimed Revista Médica Granma 24:266-276.

Fraceto LF, Paula E (2004) Anestésicos locais: interação com membranas de eritrócitos de sangue humano, estudada por ressonância magnética nuclear de H e P. Química Nova 27:66-71. 
Franco DF, De Negri D, Remuska RD, Alves ML, Sacco SR (2007) Alterações no hemograma de cães causadas pela refrigeração da amostra. Revista Científica Eletrônica de Medicina Veterinária. Publicação Científica da Faculdade de Medicina Veterinária e Zootecnia de Garça/Famed 8:1-5.

Gonçalves BAL, Vianna LR, Andrade CC, Oliveira JSG (2020) Anestésicos locais e a ação antimicrobiana, uma opção em microrganismos multirresistentes: Revisão de Literatura. Revista V \& Z Minas 145:29-32.

Jiménez JAG (2010) Posible Efecto de la Procaina, Como Neural Terapéutico, Em La Membrana del Eritrocito Humano In Vitro. Maestría thesis, Universidad Nacional de Colombia, Colombia.

Júnior JC, Viana JA, Filho JDR, Favarato ES, Mata LC, Neto NA (2008) Parâmetros bioquímicos e hemogasométricos do sangue total canino armazenado em bolsas plásticas contendo CPDA-1 e CPD/SAG-M. Ciência Rural 38:378-383.

López GE, Salazar JI, Suárez EO (2012) Descripción anatómica, fisiológica y embriológica del nervio trigémino en el marco conceptual de la terapia neural, como sustrato frecuente de campo interferente. Nova Publicación Científica en Ciencias Biomédicas 10:83-100.

Molano MLB, Bonilla LBP, Dussan EHB, Londoño CAV (2014) Anatomo-functional correlation between head zones and acupuncture channels and points: a comparative analysis from the perspective of neural therapy. Evidence-Based Complementary and Alternative Medicine 1-18. Doi: 10.1155/2014/836392.

Oliveira AC, Filho JDR, Guimarães JD, Ricardo e Silva A, Dantas WMF, Bonfá LP, Farias SK (2010) Concentração de anticoagulante, tempo e temperatura de armazenagem sobre os parâmetros hematológicos no hemograma automatizado. Ciência Rural 40:25212526.

Pires BCS (2012) Conceção de um dispositivo de micro-cromatografia hidrodinâmica para separação de células sanguíneas e visualização do mecanismo de separação. Dissertação de Mestrado, Escola Superior de Tecnologia e Gestão, Instituto Politécnico de Bragança, Portugal.

Quattrer TM (2016) A eficácia da acupuntura chinesa para o tratamento da síndrome dolorosa miofascial. Monografia, Escola Brasileira de Medicina Chinesa, São Paulo.

Ramos LC, Pintarelli GB, Luz G, Suzuki DOH (2014) Estudo da condutividade elétrica de suspensões de células biológicas. XXIV Congresso Brasileiro de Engenharia Biomédica.

Reuter URM, Oettmeier R, Nazlikul H (2017) Procaine and Procaine-Base-Infusion: A Review of the Safety and Fields of Aplication after Twenty Years of Use. Sciforschen Clinical Research 4:1-7.

Santos JS, Lorena SERS, Joaquim JGF, Belli M (2020) Implante de ouro e auto-hemoterapia menor como terapia de transtornos articulares em cadela - relato de caso. Revista Intellectus 56:5-17.

Sousa RS, Barros IO, Tavares MD, Sousa IKF, Oliveira GB, Minervino AHH, Junior RAB (2012) Lesões de armazenamento durante a conservação de sangue nas diferentes espécies: uma revisão. Acta Veterinaria Brasilica 6:68-79.

Seniv L, Simionatto M, Cruz BR, Borato DCK (2017) Análise da temperatura, do tempo e da relação sangue/anticoagulante no hemograma. RBAC 49:181-188

Speransky AD (1954) Bases para una nueva teoría de la medicina. Buenos Aires: Psique.

Suzuki DOH (2009) Estudo da condutividade elétrica de suspensões de eritrócitos de ratos durante aplicação de campos elétricos intensos: teoria, modelagem e experimentação. Tese de Doutorado, Universidade Federal de Santa Catarina, Florianópolis, Brasil.

Toscano TF, Bonilla BLP (2012) Los princípios de La terapia neural desde lós fundamentos del nervismo hasta La neurociencia actual. Revista de La Universidade Industrial de Santander 44:57-65.

Vianna LR, Gonçalves BAL (2016). Nasce uma nova especialidade na Medicina Veterinária Brasileira: Terapia Neural e Odontologia NeuroFocal. Revista V\&Z Minas 13:16-21.

Vianna LR, Gonçalves BAL (2017) Entenda a terapia neural. Revista CFMV 74: 44-47.

Vianna LR, Gonçalves BAL (2020) pH e condutividade do cloridrato de procaína em diferentes concentrações utilizadas na terapia neural. Multidisciplinary Science Journal 3:e2021002:1-5.

Weinschenk S (2012) Neural therapy - a review of the therapeutic use of local anesthetics. Acupuncture and related therapies 1:5-9. 